International Journal of Instruction e-ISSN: 1308-1470 • www.e-iji.net
July $2019 \bullet$ Vol.12, No.3

p-ISSN: 1694-609X

pp.O $341-358$

Received: 16/09/2018

Revision: 01/04/2019

Accepted: 08/04/2019

Online First:05/05/2019

\title{
Working in Groups outside the Classroom: Affective Challenges and Probable Solutions
}

\section{Tanjila Ferdous}

Lecturer, BRAC Institute of Languages, BRAC University, Bangladesh, tanjila@bracu.ac.bd

\author{
Abdul Karim \\ Corresponding author, Lecturer, BRAC Institute of Languages, BRAC University, \\ Bangladesh,abdul.karim@bracu.ac.bd
}

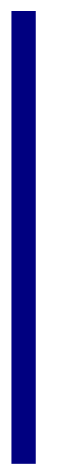

Group work is a common strategy of collaborative learning, practiced both inside and outside classroom. Irrespective of the subject matter, learners, either being assigned by the teachers or being self-employed, tend to carry out group work. It is evident that often learner experience various difficulties when they are involved in group work outside rather inside the class. Pertinently, this study aimed at identifying the difficulties undergraduate students face outside the class and presenting some effective ways of overcoming them. The study undertook Tuckman (1965), Connery (1998), Beebe and Masterson (2003) and Barkley et al. (2014) to elicit theoretical ground. Mixed -method research strategy was applied. Findings of the study suggested that learners witness problems in forming, storming, and performing stages. Individualism also impeded their group work. Participants of the study called for teachers' monitor to diminish problems.

Keywords: collaborative learning; EFL; group work; challenges; solutions; undergraduate students

\section{INTRODUCTION}

Due to the passage of time, pedagogy in different contexts has undergone visible changes. The concept of learning has been shifted from individual account to collective endeavour. Nowadays educators underscore more on creating a collaborative learning environment. Collaborative learning environment have been emerged in the spirit of replacing conventional lecture-oriented classroom with a student-cantered one. With regard to language learning in such environment, communicative Language Teaching (CLT) underpins the principles. According to Larsen and Freeman (2000), CLT incorporates activities that are often accomplished by students through group and pair work, creates the essence of collaborative learning. Eventually, students learn from each

Citation: Ferdous, T., \& Karim, A. (2019). Working in Groups outside the Classroom: Affective Challenges and Probable Solutions. International Journal of Instruction, 12(3), 358-341. https://doi.org/10.29333/iji.2019.12321a 
other. Furthermore, working in groups caters better understanding of the content (Sansivero, 2016). In addition, it paves an avenue for the students to solve problems, provided that students receive frequent assistance from the group members. As regards collaborative learning, the generic scenario concerns students' participation in smallgroup activities in which they share knowledge and expertise. To elaborate, collaborative learning is featured by positive interdependence, where students have shared belief that individual's better performance in a group secures better performance of the entire group (Johnson. et al., 2014). On top of that, team success demands hard work, and therefore, individual contributions must be assured. Moreover, equal participation is highly encouraged to ensure a successful team work. Yet ensuring equal participation is not easy to achieve. As Freeman and Greenacre (2011) propounded, students prone to experience problems due to lack of equal participation in the journey of team work. Thus, to ensure individual participation, the processes of group work must be adopted. It is also important to embrace the challenges students often experience when they attempt to attain a successful group work. Besides, being cognizant about the beneficial factor rendered by collaborative learning students seem to cringe and groan when they asked to work in group (Burke, 2011).

Unarguably, students are featured with diverse characteristics. As such, in a large group individual learner differences have obvious visibility, as identified by Witt (2014). Accordingly, as he illustrates, when a new task is assigned to a team, the initial impression engulfs them is that working together to accomplish the task is challenging but not unattainable. This happens in the dissatisfaction stage of team development when the team recognizes the distinction between what is expected from them and the reality they face to achieve that (Witt, 2015). Furthermore, Barkley, Cross and Major (2014) identify the difficulty generated by poor interpersonal skill of group members. In addition, as identified, group members may possess low self-monitoring; they may not be accultured to the effective verbal communications. Eventually, the group work may end up with limited success. As regards the challenges, Beebe and Masterson (2003) explicate that individual may suffer from the pressure to agree or to conform to the opinion of the majority. It may direct him/her to agree to an impractical decision or solution to avoid conflict. Conversely, individual can practice monolithic supremacy in the group, and thereby, dominate others in discussions. Sometimes, group members exert pressure on others to accomplish the task. Burke's (2011) study reported on the challenges students face while working in group outside the class. The problems concern individual learner differences, workload distribution, poor communication, lack of individual accountability, confusion on the material, coordinating schedules and lack of proper place. Ultimately, such phenomena potentially lower the group achievement.

With regard to the solutions to the aforesaid challenges, studies suggested numerous ways that may pave the success of collaborative learning. Firstly, Barkley, Cross and Major (2014) highlighted the necessity of equipping members with effective interpersonal skills beforehand so that they can be courageous and successive to the group. Beebe and Masterson (2003), in contrast, call for orienting group members to the goals and objectives of group and assigning them accordingly. Moreover, undertaking others' views, Barkley (2011) accumulated some strategies that may direct to the 
trajectory of success in group work. Barkley pointed out , (1) students should be wellinformed about the aim and objectives of the project (Davis, 1993); (2) they should be well- known to the learning objectives; (3) they should be well-equipped with the skill required to perform group work; (4) they should be familiar to constructive criticism (Fiechtner \& Davis, 1992); (5) they should devise a plan of action to accomplish the task; (6) instructors should also inform students about the benefit of group work (Freeman and Greenacre, 2011); (7) instructors should create ways to handle unproductive members. Finson and Ormsbee (1998) shed light on rubrics which are perceived beneficial for evaluating group work and increase the chances of group success. Wright and Lawson (2005) similarly found that making a bridge of inside and outside class work encourages students to spend more time preparing for class, and having conversations with team members outside of regular class.

Although these issues and solutions related to group work inside the class have been identified in few studies (e.g., Witt, 2015; Barkley et al., 2014; Fiechtner \& Davis, 1992; Beebe and Masterson, 2003; Burke, 2011), there is a lack of well-grounded details of how students are facing difficulties while working in group outside the class and how these problems can be solved. The aim of this article is to address the challenges or difficulties students are facing and presents some effective ways of overcoming them. The present study was guided by the following questions:

1. What are the challenges faced by the students when they get involved in group work?

2. What are the effective ways to overcome the challenges?

Such study is important in any context because the function of group work is not curtailed in academic operations; rather it has wider implications in relation to students' professional life. This study attempted to reveal the extent to which students experience various problems when being assigned to group work and to suggest probable solutions. Once the problems are addressed with proper solutions, the country will witness efficient workforce in future. The following parts of the article concerned problem statement theoretical and conceptual framework, method of the study, findings and discussion, and conclusion.

\section{Problem Statement of The Current Study}

The setting of the current study concerned an institute in a university (explained in 'method of the study' section). This institute is responsible to develop English language proficiency for the students. In this institution, a reflection meeting takes place on every Thursday. In this meeting, teachers usually share their reflections regarding the lessons they teach throughout the week. Typically, teachers shed light on their views about the lesson, challenges experienced by them and attempts contrived by them to overcome challenges.

Teachers' elicitations during reflective meetings suggest that group work allows students to explore and apply concepts beyond the scope of lectures, but collaborative learning has drawbacks too. Personalities, attitudes, schedules and confusion on the material can result in less-productive group work outside the class. In every semester, it has been 
observed in different language courses that many students are struggling while doing the group work out of the class for significant reasons. To begin with, group work completed outside class time requires members to coordinate already busy schedules to find time to meet. Groups need to meet periodically, even if the work is delegated and completed individually. The group meetings allow members to discuss the project, synthesize individual parts and prepare for class presentation components of the assignment. Finding a chunk of time to complete all of the collaborative work is often difficult with varied schedules among the group members. Secondly, in an ideal group, all members contribute equally. In reality, many groups include at least one member who wants to let everyone else do the work. Splitting up the workload equally is often a challenge, even when all members are willing to participate, as some components of the project naturally require more work than others. Some students are reluctant to participate equally in group. Either they wait for the last hour to do the work which is left or depend on others. If they work with friends, then they try to impose the work load on their friends and if they are competent enough to catch the content quickly then it will not disrupt their production that much. Sometimes it is hard to understand who worked hard and who did not. Thirdly, conflicts often arise when a group of people work together. Different personalities are not always compatible, especially when group contains one or more opinionated members. Different background experience affects individual perspectives and sometimes adds to the conflict. Conflict can push the group toward genuine discussion that improves the project, but too much conflict negatively affects the group dynamic and wastes time. Furthermore, some troublemaker students enter late in the class on group presentation day. Due to this reason, teacher cannot start the class on time. Thus, students and teacher face problems while managing the time. Additionally, if one group member comes late then other members also get tensed and they get nervous about their performance. It also hinders the sequence of the presentation. Moreover, there are such students who do not keep their words, do not come on time after matching the schedule and stop making contact before the production day. For these students, other serious students get depressed and unmotivated. Finally, some students are much introvert less communicative and inactive in nature. Working with them is a challenge for active students. Most of the time they try to pull them up but when they cannot see much differences they get hyper and stop working with them and later on they take the whole charge. From their responses regarding the challenges students face while working in group inside and outside the class, a holistic view can be found.

\section{Theoretical Framework}

In a group, issues can occur in various levels. For instance, the first difficulty experienced by a group regards the formation of it. In the group development phase, according to Tuckman (1965), issues can be yielded from five stages namely forming stage, storming stage, norming stage, performing stage and adjourning stage. In the forming stage, problems may take place if the group members do not know each other and fail to shape mutual expectation. Similarly, in the storming stage, learners may experience problem to be committed to the group. In the norming stage, group members may face challenges to elicit group norms and the role of the individual member and 
relationship among people. Since performing stage deals with the performance of the group members, difficulty may be seen in terms of individual performance. In the final phase - adjourning phase - the group work is supposed to be done, yet difficulty may arise from the question of whether or not the group work is done perfectly.

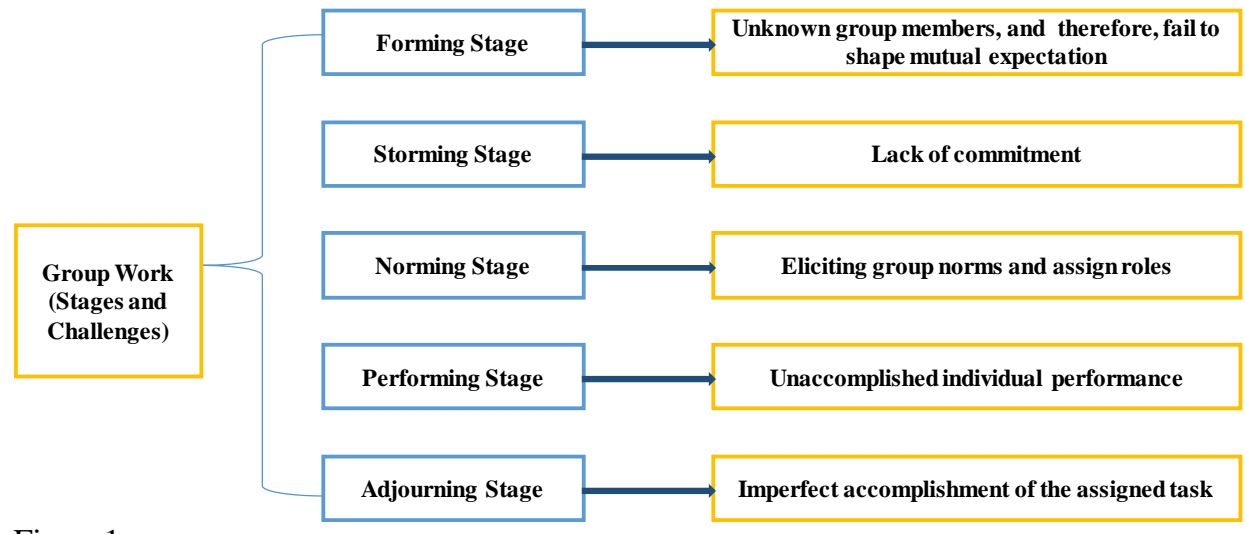

Figure 1

Tuckman's (1965) elicitations regarding affective factors in different stages, Source: Author

Burke (2011) explicated that challenge may rise at the very beginning while forming the group due to individual learner's differences. Heterogeneous biography of the learners may negatively affect the dexterity of the group. As Connery (1998) elucidated, differences in learner performance, ethnicity, gender and academic strengths and weaknesses of the learners can also belittle the collective performance of a group.

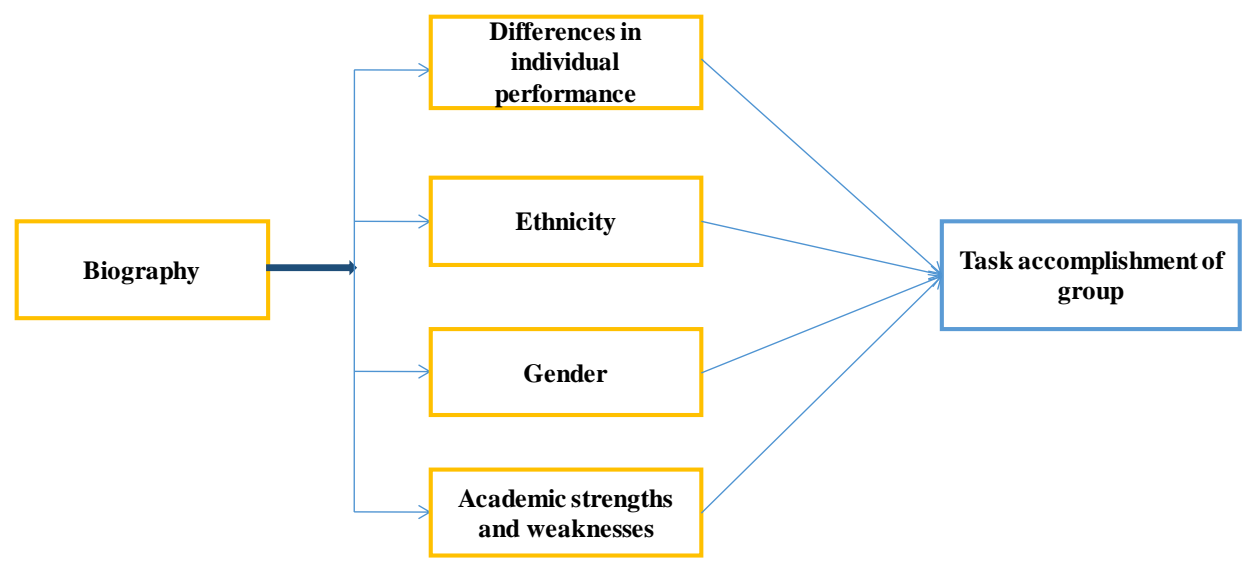

Figure 2

Connery's (1998) elicitations regarding affective factors to group work, Source: Author 
Apart from the aforementioned difficulties, groups may suffer from monolithic supremacy exhibited by individual member. Beebe and Masterson (2003) accord that individual can play domineering role in the group which may trivialize the contribution of other members in the group. Conversely, it is also evident that group members tend to rely on individual to accomplish the assigned task (Freeman \& Greenacre, 2011), which also challenges the continuation of group work. Whatever the phenomenon is, the group members or member suffer a lot out of these. Consequently, these preclude the outcome of group work.

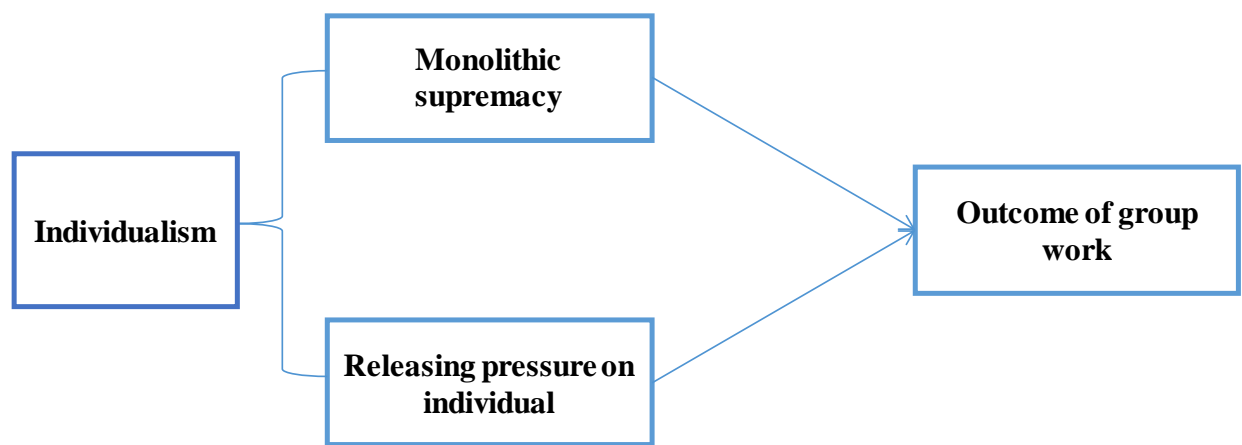

Figure 3

Individualism as an affective factor to group work, Source: Author

Barkley et al. (2014) identified the collective reluctance of the students to participate in group work. It happens when the group members share equal talent, and therefore, they do not enjoy working together in the group to accomplish the assigned task. As such, belligerence of the group members may result in the unsuccessful accomplishment of the given task.

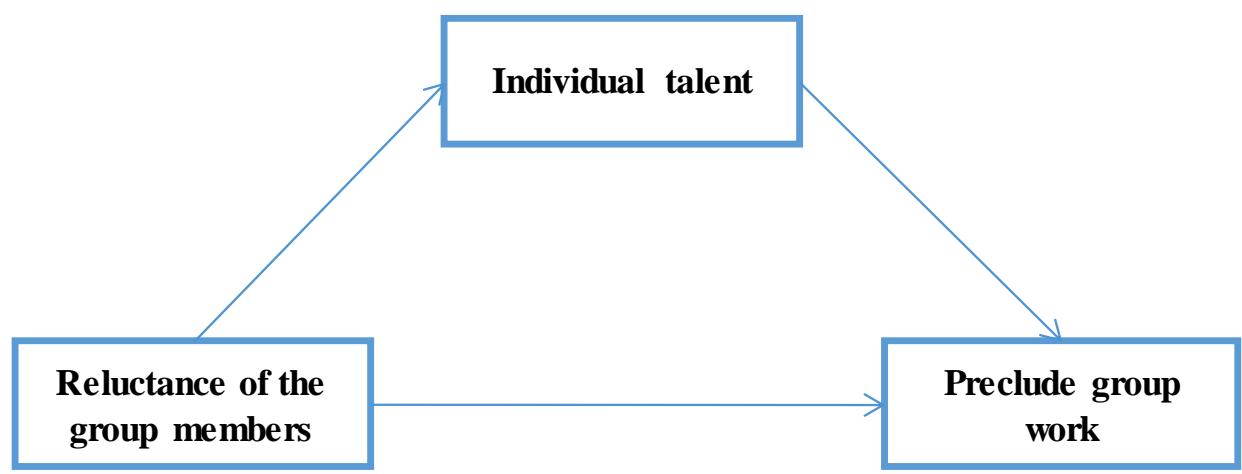

Figure 4

Reluctance as an affective factor to group work, Source: Author 


\section{Conceptual Framework of the Current Study}

The current study undertook investigation in to the challenges faced by the students when they work in group outside classroom. In particular, the current study intended to identify the extent to which certain issues are belittling group activity outside the classroom. Being more focused, the study undertook some problems shared by the teachers to a larger scale. Such problems tend to rise from forming stage to everywhere of the theoretical grounds that elicited issues associated with group work beyond classroom. Given below is the conceptual framework of the study.

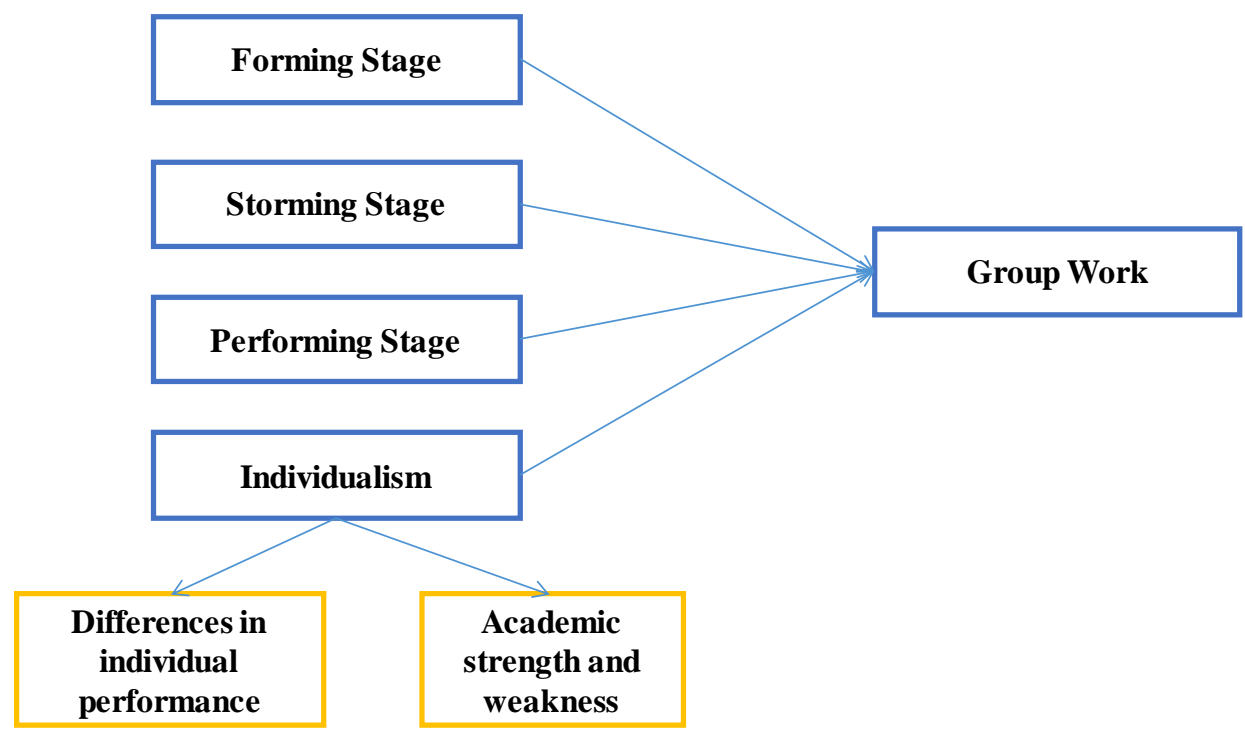

Figure 5

Conceptual framework of the study, Source: Author

\section{METHOD}

This section was developed to highlight the context of the study. Additionally, data collection procedures, participants of the study and data analysis were also briefly discussed in this section.

\section{Context of the Study}

The present study was conducted in Bangladesh, an EFL context as identified by Ali and Walker (2014) building on Nunan and Carter's (2001) view that defined a context as EFL one, if the foreign language, i.e., English gets exposed only to the classroom. However, proficiency in English is perceived as the essence of producing globally conducive citizens (Karim \& Mohamed, 2019). As such, the country undertakes initiatives to equip its citizens with the ability to communicate in English in diverse 
platforms (Karim, Mohamed, Ismail \& Rahman, 2018). As part of national initiative, schools and colleges and universities are employing deliberate effort to develop citizen's communicative ability in English (Karim, Shahed, Rahman, Mohamed, 2019).

The current study was conducted in a private university named A in Bangladesh. It operates an institution named B in the spirit of improving English language proficiency of university students, and eventually, satisfies the national need. In the following sections the details of this institution were elaborated. Initially, the sketch in relation to A university was drawn. After that, the functions of $\mathrm{B}$ institution were rigorously highlighted. It is noteworthy that the university website rendered authentic information mentioned below.

A University follows a liberal arts approach to education which nurtures fresh ideas and gives new impetus to the field of tertiary education. It ensures a high quality of education and aims to meet the demands of contemporary times.

B is an institute of A University started its journey as English Language Program (ELPro) in 2005. The purpose of the program was not only to enhance the students' English language skills to facilitate learning in their chosen fields, but also to enable effective oral and written communication. B focuses on implementing student-centered and creative language teaching techniques by developing modules based on students' proficiency level. This not only helps avoid having mixed ability classes, but also ensures small classes with excellent interaction between teachers and learners.

B institute offers well-designed and comprehensive courses in order to facilitate the English language requirements of the university students. For the undergraduate students, a range of 6 modular courses that range over from Intermediate to Upper Intermediate, Advanced Proficiency levels, and 2 specialized courses for advanced students only. From these courses, ENG 091, known as Foundation Course in English, (Non-credit) course is designed for the intermediate level students to improve all four language skills- listening, speaking, reading and writing. The course is divided into two parts, each dealing with one pair of skills- the speaking and listening is one pair and the reading and writing is the other. Besides, active participation of the students in the class proceedings is encouraged and enforced to create better effect of learning. ENG 101, known as English Fundamentals (3 credits) course, is designed for the students at an upper intermediate language proficiency level. To sharpen all four language skills, the strand is parted into two pairs of skills - the speaking and listening pair and the reading and writing pair. It focuses on writing academic papers, analysing reading materials and grooming students' listening and speaking skills, further emphasizing on strategies of the language skills. ENG 102 known as English Composition (3 credits) is designed for advanced level students, and is therefore, focused on developing their capacity of critical reading and academic writing skills. The course is heavy founded on extracting and developing the students' critical reading and critical thinking abilities. ENG 103, known as Advanced Writing Skills and Presentation (3 credits), is a course designed for students who possess required proficiency in academic writing and consequently, aspire for achieving expertise in organized creative writing and critical research. Additionally, B institute offers Pre-University, which is a unique course designed for those students 
who proved themselves competent in their respective disciplines during the admission test except in English.

B institute focuses on implementing student-centered and creative language teaching techniques by developing modules based on students' proficiency level. The students are definitely encouraged and enforced to actively participate in the classroom activities. All of the courses in B institute, is learner-centred, and encourages and enforces active student participation.

As it is promoting interactive classroom it has included such activities where students get chances to work in pair and group. Most of the times when students get to know about group work for the first time they get so excited. However, some of their feelings get changed due to the challenges they face while doing the group works. Students belong to ENG091 and ENG101, usually experience diverse challenges.

\section{Methodology}

This paper entailed a mixed-methods approach (Bryman, 2006; Creswell 8c Piano Clark, 2007; Greene, 2008; Johnson \& Onwuegbuzie, 2004; Tashakkori \&Teddlie, 1998; Teddlie \& Tashakkori, 2003). This research design was based on the "premise that the use of quantitative and qualitative approaches in combination provides a better understanding of research problems than either approach alone" (Creswell \& Piano Clark, 2007, p. 5). For mixing quantitative and qualitative data in a single study, this growing field of mixed methodology recommends diverse rationales, objectives, and strategies (Greene, 2008; Caracelli \& Graham, 1989; Johnson \& Onwuegbuzie, 2004; Creswell \& Piano Clark, 2007). Data from the survey questionnaire and interview was analyzed by undertaking the theoretical grounds and the iterations from previous studies (Hamid, Sussex \& Khan, 2009).

\section{Participants}

This research provided data of 250 undergraduate students from A University. They were first year students from different departments like, BBA, English, Architecture, CSE etc. They were all aged from 19 to 20 years and there was a combination of both male and female students. Survey questionnaire and interview have been used as instruments for this research. This study undertook data from ENG091-Foundation Course in English (Non-credit) and ENG101-English Fundamentals (3 credits). This was done since they got acquainted with group work for the first time in the university life. Like all other courses, these two courses were also learner-centered, and encouraged and enforced active student participation; these courses included such activities where students got chances to work in pair and group. As such, it became conspicuous that ENG 091 and ENG 101(Fresher- directly entered in the course based on admission test) students were the first customers of group work. Nevertheless, ENG 102 and ENG 103 students had the acquaintance with group work. Consequently, they had fewer tendencies to experience divergent difficulties, in comparison to their ENG091 and ENG 101 counterparts. 


\section{Survey Questionnaire}

A survey questionnaire was employed to apprehend the remarks of the students regarding the extent to which certain issues are negatively affecting their group work outside the classroom. The questionnaire contained some items that potentially covered the horizon of the problems students faced when they worked outside the classroom. To develop the questionnaire, the study explored wide range of literature. Moreover, the study incorporated the common thoughts shared by the teachers. Finally reviewing the literature and incorporating expert opinion, the study employed the questionnaire that was containing eleven items. On a five point likert scale (ranging from never to always) students here asked to tick to the respective statement. The questionnaires were distributed among the 268 students. However, due to incompletion and double stance, responses of 18 students were excluded. Finally, responses of 250 students constituted the data for current study.

\section{Interview}

We have administered semi-structured interview and, as recommended by Creswell (2005). The number of respondents in this regard was eight. The interview protocol was adapted from Stockwell (2015) and Wang (2008). Moreover, the instruments were piloted before data collection, where some of the questions were excluded due to redundancy and arranged in the structured way under each research question; thus, it became easy to analyze data in the thematic manner (Cohen, Manion, \& Morrison, 2013).It is essential part of the study since the quality of the findings depends on the quality of instruments that are used as well as validate the expected results (Cohen, Manion, \& Morrison, 2013).We recorded the interviews and transcribed. After that, the interview data wad cross checked with the participants, which is member checking, a process that is used to establish validity and credibility the qualitative study (Creswell \& Poth, 2017). Eventually, the transcription was crosschecked with the participant students.

\section{FINDINGS}

This section subsumed the data elicited through survey questionnaire and semistructured interview. Two types of data were presented separately to make it readerfriendly.

\section{Quantitative Data}

According to the questionnaire survey in relation to the frequency of their involvement in group work, it was found that $60 \%$ of the students often got engaged to group works while $30 \%$ claimed that they always participate in group works. Only $10 \%$ of the respondents claimed that they did it sometimes. ". We generated this question to embrace the frequency of students' involvement in group work. As such, it was identified that almost all the students had consistent exposure to group work.

However, the main aim of this study was to figure out the difficulties students face outside the class while working in group. Pertinently, questions were administered based on those difficulties. Dealing with busy schedule, majority of the respondents often 
faced difficulties. After that, 50\% of the participants affirmed that they often faced difficulty while sharing opinion in discussion. In addition, splitting up the work load equally was often a challenge for the majority. Furthermore, $48 \%$ of the participants claimed that some members missed several meetings. Besides, 55\% of the respondents claimed that they could not take decision due to the absence of one /few members/ members. Moreover, majority of the students also reported that some members relied too heavily on others to do the work, and were reluctant to participate equally in group. Along with that, they also encountered dominating group member, who prone to control the entire work. On top of that, $60 \%$ of the students claimed that they often could not get enough response from shy students, creating another dimension of difficulty for them. As regards additional burden, majority of the participants affirmed that they were often imposed with unwanted role or task. Besides, majority of the students also complained that few members stopped communicating before the day of presentation and assignment submission. In the same vein, most of them confirmed that few members of the group were found absent on the day of presentation. Additionally, $60 \%$ of the students confirmed that they could not share the name of the troublesome members in front of teacher due to the fear of misunderstanding. Most of the participants found that there was shortage of motivation among group members. Finally, Majority also claimed that they suffer from lack of suitable spaces for preparation and practice.

Table 1

Students' response to survey questionnaire

\begin{tabular}{|c|c|c|c|c|c|}
\hline $\begin{array}{l}\text { Difficulties students faced while working in group outside the } \\
\text { class }\end{array}$ & Never & Rarely & Sometimes & Often & Always \\
\hline It was hard to coordinate busy schedules & $0 \%$ & $0 \%$ & $25 \%$ & $65 \%$ & $10 \%$ \\
\hline Faced difficultly while sharing opinion in discussion & $10 \%$ & $0 \%$ & $30 \%$ & $50 \%$ & $10 \%$ \\
\hline Splitting up the work load equally was a challenge & $0 \%$ & $0 \%$ & $20 \%$ & $60 \%$ & $20 \%$ \\
\hline Some members missed several meetings & $8 \%$ & $0 \%$ & $28 \%$ & $48 \%$ & $16 \%$ \\
\hline $\begin{array}{l}\text { Could not take decision due to the absence of one /few member/ } \\
\text { members. }\end{array}$ & $0 \%$ & $0 \%$ & $45 \%$ & $55 \%$ & $10 \%$ \\
\hline $\begin{array}{l}\text { Some members relied too heavily on others to do the work and } \\
\text { were reluctant to participate equally in group }\end{array}$ & $0 \%$ & $0 \%$ & $20 \%$ & $55 \%$ & $25 \%$ \\
\hline One of the group members tried to control the entire work & $12 \%$ & $0 \%$ & $20 \%$ & $36 \%$ & $32 \%$ \\
\hline Could not get enough response from shy students & $0 \%$ & $8 \%$ & $24 \%$ & $60 \%$ & $8 \%$ \\
\hline Was imposed with unwanted role/task & $0 \%$ & $8 \%$ & $60 \%$ & $28 \%$ & $4 \%$ \\
\hline $\begin{array}{l}\text { One/few members stopped making communication before the } \\
\text { presentation day/assignment submission date }\end{array}$ & $0 \%$ & $0 \%$ & $40 \%$ & $60 \%$ & $0 \%$ \\
\hline One/few members did not show up on the day of presentation & $0 \%$ & $10 \%$ & $60 \%$ & $30 \%$ & $0 \%$ \\
\hline $\begin{array}{l}\text { Could not share the name of the troublesome members in front of } \\
\text { teacher due to the fear of misunderstanding }\end{array}$ & $0 \%$ & $16 \%$ & $24 \%$ & $20 \%$ & $60 \%$ \\
\hline There was lack of motivation among group members & 0 & 0 & 64 & 24 & $12 \%$ \\
\hline
\end{tabular}

Source: Author

\section{Interview data analysis}

We administered questions in order to embrace the challenges faced by the students, when they involved in group work outside the class. The answers of the questions were presented chronologically. Our first research question intended to identify the difficulties students usually experience. Additionally, we attempted to trace the initiatives taken by the students to reduce the challenges. 


\section{Challenges in group work}

In response to the first research question that regarded difficulty, students highlighted different challenges that potentially affect the success of group work.

\section{Finding convenient time}

Students articulated that fixing a convenient time is the biggest problem, working in group outside the class. For instance, S-1 highlighted,

Our group members are from diverse major areas. In the language class, we have peers from Computer Science Engineering (CSE), Electrical and Electronics Engineering (EEE), Bachelor of Business Administration (BBA). As such, it becomes difficult for us to fix a convenient time to sit together to accomplish our task.

\section{Maintaining communication}

Communicating with group members shapes another difficulty for the students. As interview data suggested, often members do not receive phone calls, end eventually they are absent in meetings.

\section{Assigning task to individual}

Respondents also claimed that distributing content among the group members while working was challenging because some of them did not want to participate equally. Besides, sometimes there were too many members by less content and sometimes it was difficult to get everyone's attention on work. They also claimed that reluctant member seeks for readymade content and relied heavily on friends.

\section{Monolithic supremacy}

Some of them claimed one used to dominate the group such as, he or she wanted to take the interesting part and tried to impose unwanted work on others, did not give chance to talk or share opinion etc.

\section{Grouping in group work}

Some members also get panicked in each silly matter and some members make grouping in the group.

\section{Dealing with troublesome members}

Our second question attempted to generate students' view on how to deal with the troublesome members.

\section{Seek for teachers' intervention}

Students' elicitation suggested that teacher should secretly monitor the group work and should sit with those who do not contribute and consult them by motivation. They also elaborated that teacher should identify them and give them more responsibility later monitor them by taking report from leader. 


\section{Distributing easy task among troublesome members}

They claimed that troublesome members can be used for easy task or where they are good at and they should be treated with patience. Moreover, report should be made on their participation and it should be discussed with teachers.

\section{Perceived teachers' role}

The third interview question sailed for embracing students' opinion regarding teachers' role to solve the challenges students face in group work. Students' verbatim indicated that teachers can play multidimensional role to solve students' problems.

\section{Explaining purpose of the task}

Students preferred teachers to describe the purpose of the group work. Teacher should relate the advantage of the work to their academic and professional concerns. For instance, as S-3 explicated, "Teacher should clearly explain the purpose of each group work always to emphasize on the importance of the work and can instruct on how to manage the work outside the class."

\section{Monitoring group's progress}

Participants of the study wanted teachers to monitor the progress of group work. To illustrate, S-4 sated, "Teacher should open a group on Facebook where students will discuss about their update of work and teacher will easily monitor their work and also will be able to give feedback and suggestions."

\section{Diverse concerns}

Teacher can also teach teamwork skills which will help the students to work collaboratively outside. According to them, teacher should listen to students' individual problem outside the class and indirectly talk about the problems in the class. Most of the students think that teacher should appoint a leader for each group. Leader will monitor the group work outside the class and keep record of each of the member's participation and also keep track of the attendance of the members in meetings. Besides, teacher should assign all the members of each group with different important role. Teacher should monitor the progress of group work from the very beginning by observing and discussing outside the class. Some of them think swapping system of group members from one group to another by their choice should be prohibited by the teacher because students have to interact with all in class which will help them to develop interpersonal skill. Teacher should take a scheduled class only to monitor student's group activities for each group work besides the orientation and presentation classes. Teacher should make all the students involved in Google doc in order to monitor their work outside the class. They preferred that Teachers should fix a time to consult each student to get their update before each presentation or assignment submission.

\section{Group members' initiatives to overcome challenges}

The final interview question of the present study intended to reveal the initiatives taken by the group members. It was reported that group members should exchange contact 
information and coordinate schedules to communicate and plan for the work from the very beginning. They should take charge to distribute the work load and responsibilities among themselves. A leader should take the responsibility seriously and all members should obey their leaders. Majority also mentioned that student can maintain a diary to write the self-reflection and report to the teacher individually on how well the group is working together, including their contributions to the group. All members should attend the meetings and participate sincerely. Students claimed that in the meeting students should listen to others effectively, encourage others to share his or her opinions and especially focus on the shy members to share their opinions and perform their roles. According to some of them equal distribution of each work should be ensured by the group members. They said, before going to teacher they should identify the problems and solve their own problems. Students should listen and take notes of all the instructions on group work given by the teacher in class so that those can help them while working. Finally, they emphasized that students should motivate less active and shy students to enhance their performance.

\section{DISCUSSION}

The study found that the first difficulty rose from dealing with busy schedule. Generally, such problem is faced in the forming stage. Tuckman (1965) suggested that group members do not know each other at the very beginning of the group formation. They have trouble to reach individual and settle time through the coordination. While generating individual opinion, students reported that they faced difficulty. Such phenomenon is the result of the prevalence of individual talent in a group. Ones with talent are reluctant to listen to others with full attention, since they can solve the problem with self-attempt. Assigning tasks equally to the group members appeared as a challenge too. It generally happens in the norming stage. As suggested by Tuckman (1965), group members may face challenges to split up work load equally among the members. Moreover, it was found that group members tend to be absent in several meetings, which generally takes place in the storming stage due to lack of commitment. On the top of that, due to individual absence, making decision became problematic. It can be interpreted in the light of performing stage or norming stage. Unaccomplished individual performance or individual absence may hinder decision making. The study reported that group members often exhibit their reliance on individual to get the work done. Beebe and Masterson (2003) articulated that the idea of individualism led group members to rely on other to accomplish the assigned task. Moreover, some members practice monolithic supremacy in the group and remain reluctant to take part in the activities. It was also reported that some members in the group tend to remain silent due to their shyness. Connery (1998) identified academic weakness that leads members to feel shy. Some participants claimed that they were often burdened with unwanted tasks, generally happened in the norming stage. The vibrant issues reported in this study were the late entrance and unavailability of some group members on the day of presentation or assignment submission. It happened due to lack of commitment, as identified in the norming stage. Furthermore, the current study revealed that group members could not convey their sufferings to the teachers because of the fear of creating misunderstanding. 
The semi-structured interview also suggested that students suffer from varied difficulties that emerged in different level of group work. The current study identified students' biography that negatively affects the collective achievement of group. Students belong to different departments. For this reason, it becomes difficult for them to settle a time for meeting, as delved in this study. Additionally, monolithic supremacy was articulated as exercised by some group members. Moreover, individualism i.e., releasing pressure on others was immensely highlighted by the participants during interview session.

The study also explored students' opinion regarding as to how to mitigate problems they witness during group work. It was reported that teachers can play a vital role to neutralize members' negative actions by secretly monitoring their work. The formation of mixed-ability groups was also encouraged by the students. Additionally, they suggested that teacher should appoint a leader for each group work who will monitor the group work outside the class and keep record of each of the member's participation and also keep track of the attendance of the members in meetings. Besides, according to them teacher should assign all the members of each group with different roles. Fundamentally, students left the major responsibilities with the teachers to eradicate problems. They reported that teachers should clearly explain the purpose and the importance of each group work at the beginning and they should monitor the students and take update of each group from the leaders. They also suggested that teacher can open a Facebook group to keep contact with the students and also monitor student's work through Google doc. Yet the group members' responsibilities such as, equally distributing tasks, identifying the problems and solving own problems before going to teacher, motivating less active and shy students, maintaining a dairy to keep selfreflections, writing reports on each student's participation and attendance outside the class meetings and undertaking sincerity had been echoed as the gateways to overcome problems.

Students' vocal in this regard is linear to Connery's (1988) explication that called for leaving the responsibility to form groups with teachers as they are cognizant about learner's performance level, academic strengths and weaknesses, ethnicity, gender and so on. Davis (1993) also recommended that teacher should be the moderator to avoid possible collisions among group members. Davis also urged teachers to monitor groups 'activity, which is in line with students' suggestions in this study. Chu and Kennedy (2011) paid potential attention to use Google Document. Teacher can undertake it to monitor group member's contribution and improvements.

\section{CONCLUSION}

In the light of various theoretical aspects, the present study solely focused on common challenges and probable solutions to perform group work successfully. Group work is an undeniable priority in a context that encourages communicative activities in the classroom. On the top of that, Larsen-Freeman (2011) exerted greater emphasis on inculcating group work which is an integral part of communicative language teaching.

Implication of the current study not just encompassed the mapping of successful group work but it also facilitates students' professional concern as well. Multinationals, 
nowadays, search for individuals who are highly inclined to team work and who have potentiality to become part of a group. As such, facilitating group work properly not only secures students' academic achievement, in particular language learning, but it also equips them with the ability to avoid self-centeredness and inculcate professional grooming.

\section{REFERENCES}

Barkley, E., Cross, K., \& Major, C. (2005). Collaborative learning techniques: A handbook for college faculty. San Francisco, CA: Jossey-Bass.

Burke, A. (2011). Group work: How to use groups effectively. Journal of Effective Teaching, 11(2), 87-95.

Bryman, A. (2006). Integrating quantitative and qualitative research: how is it done? Qualitative Research, 6(1), 97-113.

Cohen, L., Manion, L., \& Morrison, K. (2013). Research methods in education. London, UK: Routledge.

Connery, B. A. (1988). Group work and collaborative writing. Teaching at Davis, 14(1), 2-4. (Publication of the Teaching Resources Center, University of California at Davis)

Creswell, J. W., \& Poth, C. N. (2017). Qualitative inquiry and research design: Choosing among five approaches ( $4^{\text {th }}$ ed.). Los Angeles, CA: Sage.

Creswell, J. W., 8c Piano Clark, V. L. (2007). Designing and conducting mixed methods research. Thousand Oaks, CA: Sage.

Creswell, J.W. (2005). Educational research: Planning, conducting, and evaluating quantitative and qualitative research (2nd ed.). Thousand Oaks, CA: Sage Publications.

Davis, B. G. (1993). Tools for Teaching. San Francisco, CA: Jossey-Bass.

Elgort, I., Smith, A. G., \& Toland, J. (2008). Is wiki an effective platform for group course work? Australasian Journal of Educational Technology, 24(2), 195-210.

Felder, R. M., \& Brent, R. (2001). Effective strategies for cooperative learning. Journal of Cooperation \& Collaboration in College Teaching, 10(2), 69-75.

Feichtner, S. B., \& Davis, E. A. (1984). Why some groups fail: A survey of students' experiences with learning groups. Organizational Behavior Teaching Review, 9(4), 5873.

Finson, K. D., \& Ormsbee, C. K. (1998). Rubrics and their use in inclusive science. Intervention in School and Clinic, 34(2), 79-88.

Freeman, L., \& Greenacre, L. (2011). An examination of socially destructive behaviors in group work. Journal of Marketing Education, 33(1), 5-17. 
Greene, J. C. (2008). Is mixed methods social inquiry a distinctive methodology? Journal of Mixed Methods Research, 2(1), 7-22.

Greene, J. C., Caracelli, V. J., \& Graham, W. F. (1989). Toward a conceptual framework for mixed-method evaluation designs. Educational Evaluation and Policy Analysis, 11(3), 255-274.

Hamid, M. O., Sussex, R., \& Khan, A. (2009). Private tutoring in English for secondary school students in Bangladesh. TESOL Quarterly, 43(2), 281-308.

Johnson, D. W., Johnson, R. T., \& Smith, K. A. (2014). Cooperative learning: Improving university instruction by basing practice on validated theory. Journal on Excellence in University Teaching, 25(4), 1-26.

Johnson, R. B., \& Onwuegbuzie, A. J. (2004). Mixed methods research: A research paradigm whose time has come. Educational Researcher, 33(7), 14-26.

Karim, A., Mohamed, A. R., Ismail, S. A. M. M., \& Rahman, M. M. (2018). Organized Hypocrisy in EFL Teacher Training Programs. International Journal of Instruction, 11(2), 437-450.

Karim, A., Shahed, F. H., Rahman, M. M., \& Mohamed, A. R. (2019). Revisiting Innovations in ELT through Online Classes: An Evaluation of the Approaches of 10 Minute School. Turkish Online Journal of Distance Education, 20(1), 248-266.

Karim, A., \& Mohamed, A. R. (2019). Examining the Impact of an English in Action Training Program on Secondary-School English Teachers' Classroom Practice in Bangladesh. The Qualitative Report, 24(3), 441-469.

Kai-Wai Chu, S., \& Kennedy, D. M. (2011). Using online collaborative tools for groups to co-construct knowledge. Online Information Review, 35(4), 581-597.

Larsen-Freeman, D. (2000). Techniques and principles in language teaching. Oxford, England: Oxford University Press.

Larsen-Freeman, D. (2011). A complexity theory approach to second language development/acquisition. In D. Atkinson (Ed.), Alternative approaches to second language acquisition (pp. 48-72). New York: Routledge.

Oakley, B., Felder, R. M., Brent, R., \& Elhajj, I. (2004). Turning student groups into effective teams. Journal of Student-Centered Learning, 2(1), 9-34.

Stockwell, R. A. (2015). An exploratory study investigating the factors which explain Abu Dhabi Education Council's (Adec) English curriculum choice in grade 10/11 public high schools and the challenges its implementation poses for teachers. Retrieved August 24, 2018, from https://ore.exeter.ac.uk/repository/bitstream/handle/10871/17338/StockwellR.pdf?seque nce $=1$

Tuckman, B. W. (1965). Developmental sequence in small groups. Psychological Bulletin, 63(6), 384-399. 
Wang, W.-F. (2008). Teachers' beliefs and practices in the implementation of a new English curriculum in China: Case studies of four secondary school teachers. (Unpublished doctoral dissertation). The University of Hongkong, Hongkong.

Witt, D. (2015,). Four types of team conflict and how to deal with each effectively. Retrieved August 24, 2018 from https://leaderchat.org/2015/07/16/4-types-of-teamconflict-and-how-to-deal-with-each-effectively/

Wright, E. R., \& Lawson, A. H. (2005). Computer mediated communication and student learning in large introductory sociology classes. Teaching Sociology, 33(2), 122-135. 